\title{
Métodos de detecção de estro e falhas relacionadas
}

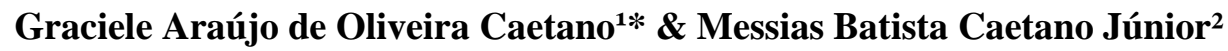

${ }^{1}$ Mestre em Zootecnia, Produção Animal;Professora Adjunto da FAJ - Faculdade de Jussara - Jussara/GO.

${ }^{2}$ Zootecnista, Especialista em Gerenciamento de Projetos.

*Autor para correspondência, E-mail: caetanozootecnia@outlook.com

\begin{abstract}
RESUMO. O presente trabalho busca realizar uma revisão sobre a detecção acurada do estro, que é um fator limitante na eficiência reprodutiva do rebanho leiteiro, sendo considerada uma das principais deficiências na reprodução bovina. A maior dificuldade que se encontra na prática da inseminação artificial é a detecção de estros que assim causa decréscimo na taxa de concepção e, consequentemente, aumento do período de serviço. A baixa porcentagem de animais detectados em estro, em alguns casos, deve-se à ausência de atividade ovariana, mas na grande maioria dos casos, o principal fator é a ineficiência na detecção de estro. O reconhecimento dos sinais do estro para escolha do método e momento mais adequado do acasalamento é uma tarefa prioritária na criação dos animais domésticos, pois influencia diretamente a taxa de prenhez, o intervalo entre partos e consequentemente, a eficiência reprodutiva do plantel.
\end{abstract}

Palavra chave: detecção de estro, eficiência reprodutiva.

\section{Methods for estrus detection and related failures}

\begin{abstract}
This paper seeks a better understanding of the accurate detection of estrus, which is a limiting factor in reproductive efficiency of dairy cattle and is considered one of the major deficiencies in bovine reproduction. The biggest difficulty lies in the practice of artificial insemination is the detection of estrus so that causes a decrease in conception rate and thus increase the period of service. The low percentage of animals detected in estrus, in some cases, due to the absence of ovarian activity, but in most cases the main factor is the inefficiency in estrus detection, which is one of the biggest barriers to achieving satisfactory rates in artificial insemination programs. Recognition of signs of estrus for choosing the most appropriate method and timing of mating is a priority task in the creation of livestock due to its influence pregnancy rate, calving interval and thus the reproductive efficiency of breeding.
\end{abstract}

Key words: estrus detection, reproductive efficiency

\section{Introdução}

De acordo com o IBGE, o Brasil é o quinto maior produtor de leite, ficando atrás da União Europeia, Estados Unidos, Índia e China. A produção de leite no Brasil aumentou 5\% em 2014, conforme o Instituto Brasileiro de Geografia e Estatística (IBGE). A produção chegou a 36,75 bilhões de litros em um ano. Em 2013, a produção leiteira foi de 35 bilhões de litros, sendo $35 \%$ a mais que os 26 bilhões contabilizados em 2007. O estado com maior produção de leite é Minas Gerais

Segundo a Associação Brasileira de Inseminação Artificial foram comercializadas no
Brasil 14,3 milhões de doses de sêmen em 2013, o que representa uma elevação do volume de aproximadamente $5,5 \%$ em relação ao ano de 2012. Do total, cerca de $41,2 \%$ das doses foram oriundas de touros de raça leiteira.

A maior parte desse crescimento deve-se ao aumento de vendas destinadas à pecuária leiteira correspondente a uma elevação de $9,6 \%$ contra apenas 2,9\% nas doses de touros de corte. Acredita-se que os preços elevados pagos ao produtor, aliado à adoção crescente da técnica de inseminação artificial como ferramenta de aumento de produtividade, tenham sido os fatores responsáveis por este incremento nas vendas. 
Parte desse aumento na produção de leite deve-se ao uso de diversas tecnologias desenvolvidas para o setor, principalmente, aquelas relacionadas à genética e ao manejo do rebanho. A detecção acurada do estro em vacas é um fator limitante na eficiência reprodutiva do rebanho leiteiro, sendo considerada uma das principais deficiências na reprodução bovina.

A Inseminação Artificial é sem dúvida um grande avanço tecnológico para o melhoramento genético animal. A maior dificuldade que se encontra na prática da inseminação artificial é a detecção de estros e assim causam decréscimo na taxa de concepção e, consequentemente, aumento do período de serviço $\left(\mathrm{n}^{\mathrm{o}}\right.$ de animais inseminados em relação ao $\mathrm{n}^{\circ}$ de animais disponíveis para IA). Fêmeas Bos indicus geralmente apresentam estro de duração mais curta (aproximadamente 10 horas), o que dificulta sua detecção. Somado a este fator, mais de $50 \%$ dos animais desse grupo genético iniciam a manifestação de cio no período noturno (entre 18:00 e 6:00 h), e cerca de $30 \%$ iniciam e encerram o estro durante a noite, dificultando o manejo e a eficácia da detecção de estro (Baruselli et al 2006).

O sucesso de um programa de IA depende de vários fatores, entre eles o mais importante é a correta orientação durante a implantação de novos programas e a condução dos já existentes. Entre as causas de baixa fertilidade em programas comerciais de inseminação artificial podem ser citadas: a falha na detecção de estro, inseminação em momento inapropriado, mortalidade embrionária, influências climáticas, fatores ligados ao manejo de cada propriedade e qualidade do sêmen.

A baixa porcentagem de animais detectados em estro, em alguns casos, deve-se à ausência de atividade ovariana, mas, na grande maioria dos casos, o principal fator é a ineficiência na detecção de estro, que se reafirma como um dos maiores entraves para a obtenção de índices satisfatórios em programa de IA.

\section{Ciclo estral}

A duração do ciclo estral das vacas varia entre 21 a 22 dias e 0 estro compreende aproximadamente 18 a 19 horas, e pode variar ligeiramente de uma fêmea para outra.

Dentro do ciclo estral ocorre a chamada fase luteínica e a fase folicular. A fase luteínica dura de 16 a 17 dias em vacas e compreende o período em que há presença do corpo lúteo, assim, a fase luteínica caracteriza grande parte do ciclo estral. A fase folicular é o período entre a regressão do corpo lúteo a ovulação. No entanto, há presença de folículos durante toda a fase luteínica, sugerindo que mamíferos domésticos apresentam fases foliculares e luteínicas sobrepostas. As células luteínicas secretam progesterona, que prepara o endométrio para implantação e também é responsável pela manutenção da prenhez, além de auxiliar no desenvolvimento das glândulas mamárias.

O hormônio GnRH (hormônio liberador de gonadotrofinas) atua na hipófise liberando altos níveis de FSH (hormônio folículo estimulante) que estimula o desenvolvimento de folículos provocando uma onda folicular. Um dos folículos se torna dominante, é o chamado desvio folicular, ocorre queda nos níveis de FSH e os outros folículos entram em atresia (degeneração folicular). A queda nos níveis de FSH é provocada pelo aumento da liberação de estrógeno, retroalimentação inibitória, o FSH diminui a níveis basais. Assim, se torna dominante $\mathrm{o}$ folículo que secretar maior quantidade de estrógeno.

Geralmente o ciclo estral apresenta duas ondas foliculares. O Bos taurus taurus pode ter de 2 a 3 ondas foliculares e o Bos taurus indicus pode ter até 4 ondas. O número de ondas foliculares depende do equilíbrio entre estrógenos e andrógenos de fontes intra e extra-ovarianas, do programa genético, escore corporal do animal, da idade, do manejo, do clima, da nutrição e da raça. A ovulação não ocorre na primeira onda folicular - o folículo entra em atresia. Isto ocorre porque a concentração de progesterona neste determinado momento impede pico de LH.

A elevação no nível de estrógeno, inicialmente induz um aumento imediato e temporário nas concentrações plasmáticas de progesterona e de outros progestágenos que estimulam a atividade de colagenase na parede folicular e atuam sinergicamente com os estrógenos na indução do comportamento de estro. $\mathrm{O}$ aumento nos níveis de estrógeno da fase pré-ovulatória acarreta o pico de LH hipofisário (hormônio luteinizante), retroalimentação estimulatória, o pico de LH é necessário para ruptura do folículo ovariano e ovulação. A elevação no nível de estrógeno e LH estimulam a síntese e liberação de PGF2 $\alpha$ (prostaglandina), o hormônio responsável pela luteólise. Assim, caso não ocorra fertilização, o corpo lúteo regride 
permitindo a maturação de outros folículos ovarianos.

Durante os ciclos estrais ocorre uma cadeia de eventos que se repete até o impedimento da luteólise pela gestação (Moraes et al., 2001). Um nível relativamente alto de progesterona é necessário durante toda a gestação, por isso ocorre secreção contínua de progesterona pelo corpo lúteo e placenta eliminando o cio e a ovulação.

O conhecimento da dinâmica folicular é necessário para a realização de protocolos de sincronização de estro e superovulação de sucesso.

\section{Estro}

Estro ou cio é o período do ciclo estral em que a fêmea está receptiva ao macho. É o período no qual apresenta receptividade sexual e normalmente ocorre em fêmeas depois da puberdade. Na espécie bovina, esse período de receptividade pode durar de 6 a 30 horas e acontece, em média, em intervalos de 21 dias. Porém, segundo alguns autores, este intervalo entre dois cios pode variar de 18 a 24 dias.

A observação de estro é um trabalho difícil e necessita experiência. A maioria das fêmeas apresenta um padrão de comportamento que se modifica gradualmente desde o começo até o fim do estro.

Identificar com precisão as manifestações do estro para o emprego da inseminação artificial é um desafio para o produtor, principalmente para aqueles que mantêm animais em regime extensivo.

O início da atividade do estro segue um padrão distinto e a maioria destas atividades ocorre durante a noite, madrugada ou começo da manhã. Algumas pesquisas mostram que mais de $70 \%$ da atividade de monta ocorre entre 19:00 e 07:00 horas. Para se detectar mais de 90\% dos cios em um rebanho, as vacas devem ser observadas cuidadosamente durante as primeiras horas da manhã, ao entardecer, e em intervalos de 4 a 5 horas durante o dia.

A detecção correta do estro é importante para reduzir o intervalo entre partos, e também para determinar o momento correto da inseminação. Van Eerdenburget al. (2002) relataram que quando a ovulação ocorre 48 horas após a inseminação apenas $15 \%$ das vacas concebem, e quando ocorre até 24 horas, $52 \%$ das vacas concebem. E ainda, Reimerset al. (1985) reportaram que $5,1 \%$ das vacas não estão em estro quando são inseminadas, e que essa porcentagem pode variar de 0 a $60 \%$ dependendo do rebanho analisado. Isso pode ser devido à inseminação realizada cedo demais, tarde demais ou detecção incorreta.

Um bom programa de detecção do estro é de fundamental importância para o sucesso da inseminação. Existem diversas técnicas disponíveis, ficando a critério do produtor a escolha da melhor que se adaptar ao seu plantel.

\section{Ciclo estral em diferentes espécies}

Nos mamíferos selvagens a atividade sexual varia com as estações do ano, já nos mamíferos domésticos, como os bovinos e suínos não ocorre esta interferência.

Em vacas e porcas o estro se manifesta regularmente durante o ano todo e a influência estacional é discreta. A fertilidade mínima ocorre em junho e a máxima em novembro em climas temperados, esta fertilidade pode estar relacionada mais ao fotoperíodo do que à temperatura e alimentação. A fertilidade na porca é mais baixa no verão do que nas outras estações, sendo menor o tamanho da leitegada.

Atuação do foto período e da temperatura são dois fatores que influenciam os ciclos sexuais, sendo o foto período mais ativo. Nos mamíferos o efeito da temperatura é raramente mencionado.

Em fêmeas suínas, a puberdade ocorre dos 5 aos 6 meses, quando ela atinge aproximadamente $120 \mathrm{~kg}$. O ciclo estral dura 21 dias, (19 a 23). O estro dura de 2 a 3 dias, nas porcas é 12 a 18 horas mais longo que em marrãs. A fêmea:

- monta e se deixa montar

- fica imóvel à pressão dorso-lombar (RTM)

- apresenta vulva entumecida e avermelhada

- perde o apetite

- fica nervosa e excitada (grunhidos e movimento de orelhas)

- apresenta micção frequiente.

Caprinos e ovinos são poliéstricos estacionais, animais de dias curtos (início da atividade sexual quando a duração dos dias começam a diminuir). $\mathrm{O}$ primeiro estro acontece por volta de 4 a 8 meses de idade, quando esta atinge $60 \%$ do peso 
vivo. A repetição do estro acontece de 15 a 21 dias, com duração média de 2 dias. A fêmea:

- abana a cauda

- presença de muco vaginal

- vulva apresenta-se inchada

- animais ficam inquietos

- berram

-sobem umas nas outras e aceitam a monta

As éguas são poliéstricas sazonais, iniciam a puberdade por volta dos 18 meses de vida, possuem o ciclo estral de 21 dias, com duração do estro de aproximadamente 6 dias. A vulva aumenta de tamanho, torna-se avermelhada, com muco transparente. A égua assume posição característica de micção, com a cauda levantada.

\section{Métodos de detecção de estro}

Das técnicas desenvolvidas para detecção de estro em vacas, a principal é a observação visual, que está diretamente relacionada ao compromisso dos responsáveis por checar esta condição, por meio do entendimento dos comportamentos e dos sinais (Diskin \& Screenam, 2000). Ávila Pires et al. (2003), constataram que a observação contínua do rebanho eliminou a possibilidade de manifestações de estro não-identificadas, entretanto, segundo Hansen (2003), é difícil, mesmo para um tratador experiente, identificar mais de $80 \%$ das vacas em estro de um rebanho de médio porte, mesmo observando as fêmeas três vezes por dia, por, pelo menos, 30min. Esta técnica, utilizada isoladamente, é geralmente ineficiente, recomendando-se a associação com tecnologias mais eficazes para detecção de estro (Kastelic, 2001; Firk et al., 2002; Roriee et al., 2002).

As técnicas eletrônicas disponíveis baseiam-se em medidas de movimentação, mudanças na resistência elétrica nas secreções do trato reprodutivo e sensores de monta (Rorie et al., 2002).

Normalmente, as fêmeas em estro se mantêm imóveis ao serem montadas por outros animais. Algumas se apresentam inquietas, caminham muito ou apresentam sinais secundários de estro, que apenas os observadores mais experientes podem detectar. O método convencional citado consiste na observação diária, feita durante uma hora, duas vezes ao dia (manhã e tarde).
Outros métodos para auxiliar a detecção visual do estro foram desenvolvidos, tais como a utilização de rufiões (touros com desvio lateral do pênis, para evitar penetração e/ou a fertilização), ou de fêmeas androgenizadas (tratadas com hormônio masculino) e equipados com buçal marcador. A técnica mais indicada para quem deseja resultados mais precisos é a observação visual com o auxílio de rufiões. Os rufiões com buçal auxiliam na identificação das fêmeas que manifestam estro fora dos períodos de observação visual. O buçal marcador é preso ao pescoço do rufião (macho) ou fêmea (androgenizada), e contém um reservatório com uma mistura de pó-xadrez com óleo queimado, que é liberada durante a monta, marcando as vacas em cio.

Existem outros métodos pra detectar estro como, pedômetro, radiotelemetria, sistema que indique a ocorrência de monta (tail-paint ou chalk), resistência elétrica do muco cérvicovaginal, métodos bioquímicos e até cães treinados para detectar odores, todos com resultados variáveis. Estes métodos podem ser utilizados isoladamente ou em conjunto, dependendo do sistema de criação e produção.

\section{Observação Visual}

A identificação visual dos sinais de estro por pessoas treinadas, baseia-se na observação das alterações de comportamento do animal e em modificações na genitália externa. $\mathrm{O}$ melhor período e a frequência para se realizar a detecção de estro ainda é muito discutido, mas a observação duas vezes ao dia, pela manhã e ao fim da tarde, ainda é a mais utilizada, com acréscimos variáveis nos índices de detecção de acordo com aumento no número de observações diárias.

Para uma adequada detecção de estro pelo método visual, o observador precisa dispor de tempo suficiente durante as observações para assegurar que verifique os sinais de estro, inclusive aqueles mais discretos, que podem ocorrer no início ou no fim do mesmo. Pode ser utilizada uma escala de escore para classificar os sinais de estro.

Quando somente este método é empregado, por volta de 20 a $40 \%$ dos estros não são identificados, e de 15 a $20 \%$ são falso positivos. Cada programa reprodutivo tem suas características próprias, considerando-se a raça, o número de animais, o grau de treinamento dos 
funcionários e o manejo adotado, o que estimula a utilização simultânea de mais de um método, para assegurar maior eficiência na identificação do estro, pois existem animais que mesmo em estro não manifestam imobilidade à monta, não devendo ser somente este o critério para detecção do estro.

\section{Através da ocorrência de monta}

Os métodos que indicam a ocorrência de monta, utilizados para auxiliar a detecção de estro são "Tailchalk" que consiste na aplicação de giz e Tailpaint (aplicação de tinta), ambos colocados na região da inserção da cauda do animal que, quando pressionados durante a monta deixam marcas no animal em estro. Entretanto, a eficiência destes métodos também depende de boa dedicação do responsável pela observação. Adesivo contendo tinta (Kamar $\left.{ }^{\circledR}\right)$, aderido no posterior do animal próximo à inserção da cauda que rompe quando montada, também pode ser utilizado.

Dispositivo eletrônico detector de monta, como o (HeatWatch ${ }^{\circledR}$ ), aderido na região da inserção da cauda do animal, ativado pela pressão feita pelo rufião ou por fêmeas durante a monta, emite um sinal por meio de frequência de rádio (Radiotelemetria) para um receptor que registra hora e dia da monta que são marcados por um software que armazena os dados e monitora o comportamento do animal por 24 horas contínuas. Uma desvantagem deste método é que seu alcance máximo é de 400 metros entre animal e o computador que armazena as informações, além de seu custo elevado.

Outro método disponível para marcar o animal montado é o buçal, que pode ser utilizado no touro ou no rufião ou mesmo em uma fêmea preparada para rufiação.

Os métodos que sinalizam a ocorrência de monta são comumente utilizados em rebanhos leiteiros, tendo sua viabilidade questionável em rebanhos de corte, principalmente devido ao seu custo elevado e às peculiaridades na criação de animais de corte, como distância das instalações em relação aos pastos e geralmente ao grande número de animais deste sistema de criação.

\section{Pedômetro}

Pedômetros, sensores colocados nas patas do animal para registrar o deslocamento do mesmo em um determinado período, pois animais em estro são quatro vezes mais ativos quando comparados com animais em outra fase do ciclo estral. Entretanto, cada animal tem que ter seu padrão individual de atividade pré-estabelecido. Este método também necessita de verificação dos sinais secundários para confirmar $\mathrm{o}$ comportamento típico de estro, portanto não é adequado para ser utilizado isoladamente. Ele pode ser comercialmente utilizado em rebanhos leiteiros de alta produção, porém com ressalvas em relação ao seu custo benefício.

\section{Métodos bioquímicos}

Os métodos bioquímicos consistem em mensurar progesterona no sangue ou leite com kits comerciais, uma vez que a elevada concentração de progesterona indica que $o$ animal está fora do período de estro, enquanto a baixa de progesterona pode indicar que o animal está em anestro, ou estro. Os métodos bioquímicos são pouco utilizados tanto em bovino de corte como de leite, principalmente pelo seu elevado custo e baixa eficiência.

\section{Resistência elétrica}

A mensuração da resistência elétrica de fluido vaginal pode auxiliar na detecção de estro, pois a condutibilidade deste fluido aumenta durante o estro, principalmente pela maior quantidade de sais. A leitura da resistência deve ser diária, porém não deve ser somente este o critério para detecção do estro, pois existem outros fatores que podem confundir com resultados semelhantes da resistência, como infecções vaginais e uterinas, doença ovariana, o que também sinaliza para a necessidade de sua associação com visualização do comportamento e sinais secundários de estro para confirmação do mesmo.

Adicionalmente, vale ressaltar que é um método que demanda muito tempo para sua realização, o que o torna de pouca aplicabilidade em criações extensivas.

\section{Rufião}

A utilização de rufiões é um método amplamente empregado para detecção de estro em rebanho de corte e leite, podem ser preparados por diferentes métodos cirúrgicos, bem como podem ser utilizadas vacas e novilhas androgenizadas. O emprego de rufiões com ou sem buçal marcador na detecção de estro em programa de IA deve necessariamente ser associado à visualização pelo inseminador, mas a eficiência na detecção aumenta quando os rufiões 
são utilizados com buçal marcador. É importante salientar que a seleção e classificação dos animais para serem utilizados como rufiões deverá ser feita avaliando principalmente aprumos, dominância social e libido.

Machos que servirão como rufiões podem ser preparados por diferentes técnicas cirúrgicas. Dentre as técnicas a serem utilizadas destacam-se a de aderência da túnica albugínea do pênis à parede ventral do abdome (Belling, 1961), a do desvio do óstio prepucial lateralmente (Carneiro, 1975), e a da fixação da curvatura caudal da flexura sigmóide do pênis.

Existe também a possibilidade da utilização de vacas ou novilhas androgenizadas com testosterona exógena como rufiões.

Para a escolha dos rufiões, os animais deverão ser avaliados quanto à manifestação de libido, sendo que bovinos Bos taurus taurus ou aqueles provenientes dos cruzamentos entre Bos taurus taurus e Bos taurus indicus são mais indicados, já que apresentam a libido com maior intensidade. Outra característica a ser observada refere-se ao peso dos animais que servirão como rufiões. Recomenda-se que o rufião esteja pesando entre 9 a 10 arrobas e a relação rufião: fêmeas situa-se, no máximo, em torno de 1:30 (Manual de Inseminação Artificial Alta Genetics, 2010). Finalmente, é importante que sua pelagem seja diferente da pelagem do rebanho de fêmeas, auxiliando a visualização dos vaqueiros encarregados da detecção do estro.

\section{Fêmeas androgenizadas}

Consiste na escolha de vacas (ou novilhas) com características fenotípicas (aparência externa) mais masculinizadas, de preferência vazias e do mesmo lote a serem inseminadas. A estas vacas é aplicado testosterona, hormônio responsável pelo desenvolvimento e manutenção das características masculinas normais, sendo também importante para a função sexual normal e o desempenho sexual.

\section{Programas de sincronização}

Muitos programas de sincronização não funcionam devido à falta de apoio técnico, diagnóstico correto nas patologias da reprodução e uso de um medicamento de forma incorreta ou sem qualidade.

$\mathrm{Na}$ instalação de um programa de sincronização o manejo é um fator importante para o sucesso, pela influência que exerce quando na obtenção dos resultados.

Os programas de sincronização para aumento da fertilidade sempre têm que ser discutidos com o fazendeiro, apresentando-lhe os custos que poderão ser adicionados como também os resultados que poderão ser obtidos, que por vários fatores e influências tanto no estro observado como no estro induzido, podem variar entre fazendas trazendo complicações para quem sugeriu.

Quando a data da manifestação do estro já é conhecida, o executor do programa pode planejar cuidadosamente a sua execução de uma maneira correta eliminando todos os efeitos negativos que ocorrem quando nas condições normais de reprodução como problemas alimentares, infra estrutura, problemas críticos antes e depois da I.A.

Alguns cuidados básicos de manejo devem ser tomados para que o programa funcione corretamente e não haja falhas como:

- O manuseio dos animais deve ser feito de uma maneira que não cause estresse ou traumatismos.

- Verificar a disponibilidade de equipamentos e produtos, para que não falte nada durante o trabalho.

- Verificar se a nutrição dos animais está sendo feita de maneira correta.

- Não vacinar, não aplicar vermífugos, não aplicar antibióticos etc. pelo menos durante o período de tratamento hormonal e durante 4 semanas no mínimo subsequentes a ele.

- Verificar se o sêmen é de boa procedência e se tem boa qualidade.

- Verificar se o inseminador tem experiência com um histórico profissional comprovado.

- Fazer um levantamento do rebanho que vai ser trabalhado, verificando quais as fêmeas cíclicas.

- Antes de realizar o programa após a separação das fêmeas cíclicas, verificar as suas condições corporais.

- Monitorar o programa, de preferência através da detecção de cio, mesmo se for utilizada a I.A. em momento fixo. 


\section{Outros métodos}

Cães treinados para detectar odor característico de estro no muco vaginal ou no leite também já foram utilizados para detectar a fase do ciclo estral, porém com sua eficiência questionada.

Utilização de Ovascan, que é um aparelho que mede a resistência do muco vaginal da fêmea, indicando quando o animal está em estro. Para as condições onde a pecuária de corte é extensiva, a desvantagem é que a avaliação para a leitura da resistência tem que ser diária.

\section{Combinação de métodos}

Dentre os métodos disponíveis para a detecção de estro, o mais utilizado é a associação da observação visual com auxílio de rufiões. Pesquisas mostram que existe um percentual considerável de animais que manifestam estros curtos, noturno e/ou diurno, que os mesmos ocorrem entre os períodos de observação de estro, podendo representar até $25 \%$ do total de animais liberados para o programa ou um acréscimo de $18 \%$ em estro detectado. Desta forma, inúmeros estros passam despercebidos durante uma estação de monta quando o método de detecção de estro utilizado é somente o de observação visual ou até mesmo com auxílio de rufiões, duas vezes ao dia.

Entretanto pesquisadores sugerem observações adicionais diurnas, por volta do meio do dia e noturnas o que, no entanto torna o programa mais oneroso. As observações adicionais noturnas e diurnas podem ser evitadas, com a associação de três métodos de detecção, observação visual duas vezes ao dia (manhã/tarde) com auxílio de rufiões munidos com buçal marcador. Para tal, devem ser considerados os animais que forem encontrados com o dorso tingido com a tinta do buçal marcador, porém não mais aceitando a monta. Estas matrizes possivelmente manifestaram estro durante a noite, se encontradas pela manhã, ou durante o dia, se identificadas à tarde.

\section{Fatores que influenciam no comportamento do estro}

A expressão e a detecção do estro variam dependendo de vários fatores. $\mathrm{O}$ tipo de abrigo (barracão, freestall, pasto, espaço para caminhar ao redor das cercas, etc.) pode determinar as chances dos animais mostrarem estro e do produtor detectar as vacas em estro. Em rebanhos maiores, mais de uma vaca pode mostrar estro ao mesmo tempo. Quando isto acontece, as chances de detectar as vacas em estro aumentam dramaticamente, pois as atividades de monta também aumentam consideravelmente. Por exemplo, duas vacas em estro ao mesmo tempo (grupo sexualmente ativo) desencadeiam o triplo de atividade de monta. Todavia, fatores como alta temperatura e umidade, vento, chuva, neve, falta de espaço e condições de solo escorregadio ou problemas de casco, tendem a diminuir a expressão do estro.

Portanto as interações que podem exercer influência sobre o comportamento de estro são estresse, adaptação, ambiente físico, clima, interação humano-animal, manejo, condição nutricional, idade, genética e a presença ou ausência do touro no lote. Desta forma, a movimentação do animal para mudança de pasto como qualquer movimentação agitada, chuvas, pode influenciar de forma negativa na manifestação clínica de estro, principalmente na verificação do comportamento de monta.

\section{Influência do fotoperíodo na expressão e detecção de estro}

A técnica de Inseminação Artificial (IA) está em franco crescimento em rebanhos de bovinos de corte em todas as regiões do Brasil e é a mais utilizada para obter indivíduos cruzados (Bos $t$. taurus $\mathrm{x}$ Bos $t$. indicus) pela facilidade de implantação nos grandes rebanhos de fêmeas em idade reprodutiva, aliada ao problema da baixa produção de touros taurinos adaptados ao nosso clima. Um dos grandes entraves para o sucesso em um programa de inseminação é a eficiência na detecção do estro. As dificuldades encontradas em outros países têm sido dirimidas através do estudo comportamental das matrizes.

A pecuária de corte está espalhada por todo o território brasileiro, mas possui maiores concentrações nas regiões Sudeste, Centro-Oeste e Norte, com importantes diferenças climáticas, como a variação na duração dos dias (fotoperíodo), a sazonalidade pluviométrica, e a própria temperatura do ar, que podem alterar o comportamento sexual das matrizes.

Para avaliar a influência do foto período, foi realizado um trabalho que utilizou a monitoração dos períodos de observação de estro em quatro fazendas localizadas no Norte e no Centro Oeste do Brasil, que fazem o uso da técnica da inseminação artificial, para compreender o efeito 
do foto período sobre o estro. Foram detectadas 4202 ocorrências de estro em 3358 fêmeas Nelore, 662 fêmeas cruzadas Limousin x Nelore, e 182 fêmeas cruzadas Red Angus x Nelore, submetidas ao mesmo manejo de detecção. A duração média do dia foi de 730,3, 750,8, 771,0 e 795,6 minutos, respectivamente nas fazendas 1 (Pará), 2 (Tocantins), 3 (Goiás) e 4 (Mato Grosso do Sul). Quanto maior a duração do dia mais estros foram detectados pela manhã. Houve diferenças entre as categorias de fêmeas quanto à ocorrência de estro, ficando concentradas as ocorrências de estro das novilhas no período matinal em todas as fazendas e em todos os grupos genéticos. Não houve diferença estatística entre os grupos genéticos dentro das categorias. As vacas solteiras comportaram-se de forma similar as novilhas não havendo diferenças estatísticas na detecção do estro. As vacas paridas tenderam de forma geral a manifestar estro no período da tarde.

\section{Influência do estresse térmico na expressão e detecção de estro}

$\mathrm{O}$ estresse reduz o comprimento e intensidade do estro. Lucy (2001) relatou que a intensidade de manifestação de estro é aumentada quando as vacas com (ET) são refrescadas. Nebel et al. (1997) relataram que vacas holandesas apresentaram 4.5 montas por estro no verão vs 8.6 no inverno. A porcentagem de estro não detectada no rebanho leiteiro da Flórida foi estimado em 76 a $82 \%$ de junho a setembro e 44 a $65 \%$ de outubro a maio (Hansen \&Aréchiga, 1999).

Estresse térmico pode envolver secreção do hormônio adrenocorticotrófico (ACTH) causando aumento na liberação de cortisol, bloqueando a secreção do estradiol e o comportamento sexual (Hein \& Allrich, 1992). Porém a elevação nos níveis de cortisol apresenta controvérsias, pois (Hansen \& Aréchiga, 1999) observaram diminuição na concentração de cortisol.

Os efeitos do estresse no comportamento de estro incluem uma ação independente do eixo hipófise-adrenal. Alguns relatos indicam que estresse causa uma redução na concentração periférica de estradiol $17 \mathrm{~b}$, embora esse efeito não tenha sido observado por (Wilson et al. 1998). As concentrações de estradiol no sangue necessárias para dar início ao comportamento de estro são pouco precisas, desta forma é impossível afirmar se vacas leiteiras com (EC) conseguem ou não atingir um limite mínimo de estradiol para manifestação de estro (Lucy. 2001). É possível que a maior razão para redução do comportamento de estro seja devido a uma inatividade física causada pelo estresse calórico.

\section{Falhas na detecção do cio}

O estro pode não estar sendo detectado devido as seguintes razões:

- Prenhez positiva.

- A vaca está em anestro no pós parto.

- A vaca está em anestro devido a desnutrição, infecção severa do trato reprodutivo, ou outros tipos de complicações do pós parto.

- A vaca têm cistos ovarianos.

- Simples falha na detecção de estro.

As falhas de detecção de estro são uma das grandes causas dos problemas reprodutivos dos rebanhos. A maioria dos períodos de estro pode ser detectada pela observação cuidadosa do gado, pelo menos duas vezes ao dia. Para isso é necessário que as pessoas envolvidas sejam treinadas e conscientizadas da importância que é a detecção para o sucesso reprodutivo dos animais.

A identificação correta do estro de uma vaca aparece como ponto crítico para a obtenção de sucesso reprodutivo nos rebanhos bovinos, estando atrelada ao estado reprodutivo da vaca e a sua aptidão para a reprodução, e aos profissionais responsáveis pela sua observação, que devem conhecer as características teóricas e práticas evidenciadas no animal em estro.

A detecção de estro é citada como o principal entrave para a implantação de um programa de inseminação artificial, comprometendo os resultados e reduzindo a utilização da técnica. Uma falha nesta etapa aumenta o intervalo entre partos, à taxa de serviços por concepção, taxa de retorno, diminuindo as taxas de concepção e a produção leiteira das propriedades, o que gera custos que podem até mesmo inviabilizar a implantação de programas de melhoramento genético. $\mathrm{O}$ estro é marcado por uma série de alterações metabólicas e hormonais que ocorrem no organismo da vaca de forma silenciosa, antes mesmo do seu início, e também pela expressão de sinais e comportamentos característicos. A ocorrência e a manifestação do estro estão vinculadas a vários fatores relacionados com $\mathrm{o}$ 
animal e também com o ambiente. Ainda, as características reprodutivas são herdáveis, variando conforme as linhagens maternas e paternas e entre raças. Os dias pós-parto, o número de lactações anteriores e a produção de leite dos animais interferem no retorno das vacas à ciclicidade e no intervalo parto-concepção. Outro fato que deve ser levado em conta são as doenças que podem acometer os animais no período reprodutivo, mascarando os sinais do estro ou mesmo suprimindo a sua ocorrência. Assim também o estado nutricional do rebanho, tanto no que se refere à quantidade dos alimentos ingeridos como a sua constituição, merece toda a atenção pela influência que têm sobre o ciclo estral. Da mesma forma as condições de estabulação, aguadas, bem-estar dos animais e ocorrência de intempéries como secas, geadas e chuvas provocam alterações na fisiologia dos animais e na visualização do estro. Assim, é necessário que a eficácia na observação de estro da propriedade seja avaliada para que as medidas corretivas em casos de erro sejam tomadas a tempo de impedir reduções nas taxas reprodutivas e perdas econômicas.

Em todo o mundo há relatos que indicam baixa taxa de serviço em bovinos inseminados artificialmente, principalmente em decorrência de comprometimentos na detecção do estro. Quando poucas vacas são detectadas em estro ocorrem significativas perdas na eficiência reprodutiva do rebanho, e comprometimento do programa de IA.

Nos EUA estima-se uma perda anual de mais de 300 milhões de dólares na indústria de leite por falhas na detecção ou pela detecção inadequada do estro (Senger, 1994). Esse comprometimento é ainda maior em rebanhos Bos indicus, cujo comportamento reprodutivo apresenta particularidades - estro de curta duração com elevado percentual de manifestação durante o período da noite (Galina et al., 1996; Pinheiro et al., 1998).

Como o Brasil possui cerca de 73 milhões de fêmeas bovinas em reprodução (Anualpec 2004), com prevalência de aproximadamente $80 \%$ de sangue zebu (Bos indicus), criadas na sua grande maioria a pasto, ocorrem significativos comprometimentos na taxa de detecção de estro e na eficiência dos programas de inseminação artificial.

Desta forma, é crescente a pesquisa sobre os conceitos teóricos e suas relações práticas com a detecção de estro, visando minimizar falhas na sua observação, otimizando índices e custos reprodutivos nos rebanhos.

\section{Anestro}

A detecção correta e eficiente do estro em vacas de leite é um importante componente de um bom programa de manejo reprodutivo. Uma vaca pode não estar sendo observada em estro por dois motivos. Primeiro, o ovário da vaca não esta funcionando adequadamente e a vaca está em anestro (não está ciclando). O segundo motivo, a pessoa responsável pela observação de estro, não está vendo a vaca em estro, porém a vaca esta ciclando normalmente. Embora o segundo motivo seja o mais comum na maioria dos casos, não é difícil encontrarmos os dois problemas em um mesmo rebanho.

A extensão desses dois motivos de falha na detecção de estro varia entre os rebanhos. A porcentagem de vacas em anestro aos 60 dias pós-parto em um rebanho de vacas Holandesas pode variar de 5 a $20 \%$. A porcentagem de falha na detecção de estro pode variar de 15 até mais de $60 \%$.

$\mathrm{O}$ anestro ou a perda de estro podem reduzir a lucratividade do rebanho significativamente, portanto nas fazendas que apresentam problemas de detecção de estro, é importante definir qual das duas causas das falhas ocorre e a partir dessa definição tomar medidas para corrigir 0 problema.

\section{Como determinar as causas do problema?}

As anotações da palpação ou exame com ultrassom dos ovários das vacas feitos pelo veterinário e a data do primeiro estro pós-parto são necessários para determinar se está ocorrendo anestro ou falha de detecção de estro. Se essas informações não estão disponíveis, o primeiro passo vai ser a coleta desses dados. Para o diagnóstico real da situação o ideal é analisar os dados de 6 meses, de pelo menos dois terços do rebanho.

- Resuma os dados da seguinte forma:

1. Exclua as vacas diagnosticadas com cisto (se mais de $15 \%$ das vacas do rebanho apresentam cisto, providências devem ser tomadas para corrigir esse problema).

2. Examine as anotações dos exames ovarianos de cada vaca nos primeiros 90 DPP. Faça uma lista com número da vaca, DPP em 
cada palpação e o diagnóstico (presença ou não de corpo lúteo - CL). Calcule a porcentagem de vacas palpadas com CL com menos de $60 \mathrm{DPP}$.

- Rebanhos de vacas Holandesas com mais de $10 \%$ de ovários sem CL aos 60 DPP tem problema com anestro (Britt, et al., 1974).

3. Calcule o número de dias entre o parto e o primeiro estro observado de cada vaca.

4. Determine a média do intervalo parto/primeiro estro observado do rebanho e a porcentagem de vacas observadas em estro antes dos 50 e 63 DPP.

- Mais de 70\% das vacas do rebanho devem ser observadas em estro antes dos 50 DPP e mais de $95 \%$ antes dos 63 DPP, em rebanhos de vacas Holandesas (Britt et al., 1974).

Se uma porcentagem pequena das vacas apresenta CL nos exames ovarianos, o problema provável é anestro.

Se uma percentagem esperada de vacas apresenta CL nos exames ovarianos, mas o intervalo parto/primeiro estro está muito elevado, o problema provável não é anestro, mas falha de detecção de estro.

O importante é cada fazenda fazer seu histórico, para saber se o problema está sendo resolvido ou se está aumentando. Pois é difícil falar qual a porcentagem ideal de vacas com CL aos 60 DPP e qual a porcentagem de vacas que deveriam ter sido observadas em estro até os 60 DPP, devido as diferenças existentes entre os rebanhos (grau de sangue, manejo alimentar, número de ordenhas, conforto térmico, entre outros fatores que afetam o retorno à ciclicidade e a detecção de estro).

\section{Como resolver o problema Anestro:}

Nutrição inadequada e infecção uterina são duas importantes causas do anestro. $\mathrm{O}$ manejo nutricional de rebanhos com problemas de detecção de estro deve ser analisado cuidadosamente, para garantir que quantidades adequadas de nutrientes, especialmente energia, estão sendo oferecidas.

Medidas para reduzir parto distócicos e retenção de placenta devem ser tomadas. Distocia e retenção de placenta geralmente resultam em infecção uterina, o que atrasa o reinicio da atividade ovariana pós-parto.
Todas as pessoas envolvidas na deteç̧ão de estro devem ser treinadas e conscientizadas da importância desse serviço.

Pesquisadores têm relatado muitas dificuldades que podem ser associadas à detecção de estros, como:

- O período do ano no qual se necessitam detectar estros, pois condições de inverno limitam a expressão do estro

- A duração da receptividade sexual em gado tropical tende a ser menor

- Novilhas exibem sinais de comportamento de estro menos característicos em relação às vacas, exigindo um maior tempo de observação

- A maioria das atividades de monta ocorre à noite

Outras dificuldades de manejo em bovinos de corte que, somadas determinam uma baixa eficiência na detecção do estro são:

- Formação de lotes durante a estação de monta (Realizado normalmente com um número grande de fêmeas e ao serem colocadas em pastos muito extensos se movimentam muito)

- Variações climáticas (ação de chuvas ou calor provoca um desconforto térmico que diminui a atividade de monta, alterando os sinais comportamentais de estro como ato de lamber, fazer e/ou aceitar a monta)

- Infra estrutura de pessoal (pessoal despreparado para realizar um trabalho que exige paciência e cuidado nas observações de estro)

- Estresse (estresse que causa nos rodeios das vacas para detecção de estros, apartações e as longas caminhadas por não existir um piquete perto do curral onde as vacas vão ser trabalhadas e inseminadas).

\section{“Cio" silencioso}

Detecção de estro é um dos fatores mais importantes do manejo reprodutivo, e as falhas de detecção contribuem de forma significativa para o declínio da eficiência reprodutiva de um rebanho leiteiro. Heersche \& Nebel (1994) após analisarem os dados de 4.550 rebanhos americanos, concluíram que a taxa de detecção de estro era de 38\%. Coleman (1993) atribuiu $90 \%$ das falhas às pessoas responsáveis pela detecção e $10 \%$ às vacas. 
Uma das possíveis causas das falhas de detecção de estro pode ser a introdução de ferramentas auxiliares de detecção de estro que podem deixar as pessoas responsáveis pela detecção menos atentas. A manutenção do bom conhecimento dos sintomas de estro, a observação o mais frequente possível e por um período adequado (30 a 60 minutos) são fundamentais para a boa eficiência de detecção de estro.

A duração e a intensidade do comportamento de estro são altamente variáveis entre indivíduos e influenciado pelo número de vacas em estro num mesmo grupo (Diskin \& Sreenan, 2000). Grupos pequenos de vacas e a parição distribuída ao longo do ano contribuem para a redução de vacas em estro simultaneamente no lote.

Implantação de um protocolo de detecção de estro com observação de comportamento de estro por um técnico treinado por dois períodos por dia de 30 minutos cada, mais a observação diária pelos outros funcionários da fazenda durante as atividades rotineiras foi capaz de detectar $65 \%$ das vacas em estro. Nesse mesmo protocolo foram detectados $9,3 \%$ de estros em vacas considerados em anestro pela análise da concentração de progesterona e 2,3\% de estros em vacas gestantes (Law et al. 2009).

Cios silenciosos ou ovulação silenciosa são problemas comumente associados com falha de detecção de estro em vacas de leite de alta produção (Shipka, 2000). A ausência do comportamento de estro antes da primeira ovulação pós-parto é atribuída à exposição a alta concentração plasmática de estradiol no final da gestação que deixa o hipotálamo num estado refratário ao estradiol (Allrich, 1994). Foi sugerido que a exposição à progesterona durante a primeira fase luteal pós-parto retira a refratariedade do hipotálamo e permitiria que a vaca manifestasse o comportamento normal de estro quando a concentração de estradiol se elevasse durante a segunda ovulação pós-parto (Kyleet al., 1992; Allrich, 1994).

King et al. (1976) e Kyle et al. (1992) relataram que de 50 a $80 \%$ das primeiras ovulações pós-parto são silenciosas, e que a partir da terceira ovulação pós-parto, $100 \%$ das vacas expressam comportamento de estro.

Law et al. (2009) estudaram 367 ciclos estrais de 90 vacas até 140 dias pós-parto e avaliando a concentração de sanguínea de progesterona, detectaram 19,6\% de estros silenciosos (72/367). Os cios silenciosos foram definidos pela não observação de comportamento de estro nas vacas (observação de comportamento de estro por um técnico treinado por dois períodos por dia de 30 minutos cada, mais a observação diária pelos outros funcionários da fazenda durante as atividades rotineiras) que pela variação da concentração de progesterona apresentavam atividade estral. A porcentagem maior de cio silencioso $(47.2 \%)$ foi detectada nas vacas no primeiro ciclo pós-parto e foi decrescendo nos ciclos seguintes. Gil et al. (1997) reportou que $48 \%$ das vacas apresentam pelo menos um cio silencioso até ficarem gestantes.

$\mathrm{Na}$ maioria dos experimentos os cios silenciosos são definidos pela não observação do comportamento de estro por técnicos treinados. No entanto, deve-se levar em consideração que isso não significa que realmente as vacas não manifestaram o comportamento de estro.

Algumas vacas não mostram interesse por outras vacas, o que pode comprometer a externalização do comportamento de estro (Ball \& Jackson, 1979). Adicionalmente a duração do estro de vacas de alta produção é menor. Van Vliet \& Van Eerdenburg (1996) relataram estros de duração de apenas 4 horas.

Portanto apesar a taxa de cio silencioso ser de aproximadamente $20 \%$, não pode ser considerada o único causador dos problemas da falha de detecção de estro das fazendas leiterias, e não pode ser usado como desculpa para a baixa eficiência da detecção.

\section{Considerações finais}

Os problemas na detecção de estro são os maiores entraves para obtenção de índices satisfatórios em programas de inseminação artificial.

O reconhecimento dos sinais do estro para escolha do momento mais adequado do acasalamento é uma tarefa prioritária na criação dos animais domésticos, pois influencia diretamente na taxa de prenhez, no intervalo entre partos, consequentemente, na eficiência reprodutiva do plantel. O auxílio do macho nesta tarefa é fundamental, afinal, por natureza ele sabe detectar uma fêmea em estro. Paralelamente, cuidados de higiene e no manejo dos animais durante a cobertura contribuem para assegurar resultado satisfatório na atividade reprodutiva. 
Implantação de um protocolo de detecção de estro com observação de comportamento de estro por um técnico treinado por dois períodos por dia de 30 minutos cada, mais a observação diária pelos outros funcionários da fazenda durante as atividades rotineiras, diminuem consideravelmente as falhas na detecção de estro (Law et al. 2009).

\section{Referências Bibliográficas}

Allrich, R. D. Endocrine and neural control of estrus in dairy cows. Journal Dairy Science. 77, 2738-2744, 1994.

Alta Genetics. Manual de Inseminação Artificial. Disponível no site: www.altagenetics.com.br/manual/images/Man ual de IA.pdf. Acesso em Julho de 2015.

ANUALPEC - Anuário Da Pecuária Brasileira, 2004.

ASBIA - Associação Brasileira De Inseminação Artificial, 2015 [online]. Disponível em: http://www.asbia.org.br. Acesso em 28 Julho de 2015.

Ávila Pires, M.F. et al. Comportamento de vacas da raça Gir (Bos taurus indicus) em estro. Arquivo Brasileiro de Medicina Veterinária e Zootecnia, 55, 187-196, 2003.

Ball, P. J. H. \& N. W. Jackson. The fertility of dairy cows inseminated on the basis of milk progesterone measurements. British Veterinary Journal. 135:537-540, 1979.

Baruselli, P.S., Sá Filho, M.F., Martins \& C.M., Nasser, L.F. and embryo transfer in Bos indicus cattle. Theriogenology, 65, 77-88, 2006.

Belling, T. H. Preparation of the teaser bull for use in beef cattle artificial insemination program. Journal Am. Veterinary Med. Associatio. 138, 670-672, 1961.

Britt, J.H.; Morrow, D.A.; Kittok, R.J. \& Seguin, S.E. 1974. Uterine involution, ovarian activity and fertility after melengestrol acetate and estradiol in early post-partun cows. Journal Dairy Science, 57, 89-92.

Carneiro, M. I. Preparação de rufiões bovinos. Técnicas cirúrgicas para formação de novo óstio prepucial. Colégio Brasileiro de Reprodução Animal. 1, 2-24,1975.

Coleman, D. A. 1993. Detectingestrus in dairycattle. USA National Dairy Database,
Reproduction. Collection, University Maryland, College Park.

Diskin, M. G. \& J. M. Sreenan. Expression and detection of estrous in cattle. Reproduction Nutrition Development. 40, 481-491, 2000.

Firk, C.A. et al. Automation of oestrus detection in dairy cows: a review. Livestock Production Science. 75, 219-232, 2002.

Galina, C.S.; Orihuela, A. \& Bubio, I. Behavioural trends affecting oestrus detection in Zebu cattle. Animal Reproduction Science. 42, 465-470, 1996.

Gil, Z., J. Szarek, \& J. Kural. Detection of silent estrous in dairy cows by milk temperature measurement. Animal Science. 65:25-29, 1997.

Hansen, P.J. Embryonic mortality in cattle from the embryo's perspective. Journal Animal Science. 80: 33-44, 2003.

Hansen, P.J., Arechiga CF, Ortiz O. Effect of prepartum injection of vitamin-E and selenium on postpartum reproductive function of dairy-cattle. Theriogenology. 41: 1251$1258,1999$.

Heersche, G., and R. L. Nebel. Measuring efficiency and accuracy of detection of oestrus. Journal Dairy Science. 77, 27542761, 1994.

Hein, K.G., Allrich, R.D. Influence of exogenous adrenocorticotropic hormone on estrous behavior in cattle. Journal Animal Science. 70, 243-247, 1992.

IBGE - Instituto Brasileiro de Geografia e Estatística -. [2015]. Estatísticas sobre pecuária, rebanho e produção. Disponível em: <www.sidra.ibge.gov.br> Acesso em: 27 de julho de 2015.

Kastelic, J.P. Computadorized heat detection. Avancement in Dairy Technology, 13, 393402, 2001.

King, G. J., J. F. Hurnik \& H. A. Robertson. Ovarian function and oesrus in dairy cows during early lactation. Journal Animal Science. 42, 688-692, 1976.

Kyle, S. D., C. J. Callahan, and R. D. Allrich. Effect of progesterone on the expression of estrus at the first postpartum ovulation in dairy cattle. Journal Dairy Science. 75:14561460, 1992. 
Law, R. A., F. J. Young, D. C. Patterson, D. J. Kilpatrick, A. R. G. Wylie, and C. S. Mayne. Effect of dietary protein content on estrous behavior of dairy cows during early and milk lactation. Journalof Dairy Science. 92, 10131022, 2009.

Lucy, M. C. Estratégias de manejo de vacas leiteiras para melhoria dos índices. Anais do V curso "Novos enfoques na produção e reprodução de bovinos, 12-18, 2001

Moraes, J. C. F.; Souza, C. J. H. \& Gonsalves, P. B. D. Controle do Estro e da Ovulação em Bovinos e Ovinos. In: Gonsalves, P. B. D.; Figueiredo, J. R.; Freitas, V. J. F. Biotécnicas Aplicadas à Reprodução Animal. São Paulo: Livraria Varela, cap. 3, 25-55, 2001.

Nebel, R.L., Walker, W.L., Mcgilliard, M.L., Allen, C.H. \& Heckman, G.S. Timing of insemination of dairy cows: fixed once daily versus morning and afternoon. Journal Dairy Science.77, 3185-3191, 1997.

Pinheiro, O.L., Barros, C.M., Figueiredo, R.A., Valle, E.R., Encarnação, R.O. \& Padovani, C.R. Estrous behavior and the estrus-toovulation interval in Nelore cattle (Bos indicus) with natural estrus or estrus induced with prostaglandin F-2-alpha or norgestomet and estradiol valerate. Theriogenology. 49, 667-81, 1998

Reimers, T.J., Ullmann, M.B. \& Hansel, W. Progesterone and prostanoid production by bovine binucleate trophoblastic cells. Biology Reproduction. 33, 1227-1236, 1985.
Rorie, R.W., et al. Application of electronic estrus detection technologies to reproductive management of cattle. Theriogenology, 57, 137-148, 2002.

Senger, P. L. The estrus detection problem: new concepts, technologies, and possibilities. Journal of Dairy Science. 77, 2745-2753, 1994.

Shipka, M.P. \& Ellis, L.C. Effects of bull exposure on postpartum ovarian activity of dairy cows. Animal Reproduction Science. 54, 237-244, 1999.

Van Vliet, J.H. \& Van Eedenburg, F.J.C.M. Sexual activities and estrus detection in lactation Holstein cows. Applied Animal Behavior Science. 50, 57-69, 1996.

Wilson, S.J., Kirby, C.J., Koenigsfield, A.T., Keisler, D.H. \& Lucy, M.C. Effectes of controlled heat stress on ovarian function of dairy cattle. Journal Dairy Science, 81, 21322138, 1998.

\section{Recebido em Setembro 9, 2014}

\section{Aceito em Novembro 4, 2014}

License information: This is an open-access article distributed under the terms of the Creative Commons Attribution License, which permits unrestricted use, distribution, and reproduction in any medium, provided the original work is properly cited. 